\title{
AIDS research cut to pay for anthrax vaccine
}

\section{Erika Check, Washington}

The Bush administration is to proceed with plans to skim more than $\$ 200$ million from research grant programmes to pay for the rapid production of an anthrax vaccine, brushing off the protests of biologists.

As a result of the decision, 375 AIDS researchers and other grant-holders at the National Institute of Allergy and Infectious Diseases (NIAID) will this year lose the initial six months of funding on their awards.

The NIAID will spend \$233 million on the research, development and purchase of a 'next-generation' anthrax vaccine by 2004 , the White House Office of Management and Budget says.

The transfer of money from the NIAID's civilian research programmes for the vaccine work is just $2 \%$ of its total research budget. But research organizations say they are afraid that the decision is a harbinger of how the NIAID's swelling biodefence mission may compromise its research programmes.

"I don't think anyone opposes doing research to make a better anthrax vaccine but that work should be funded out of the bioterrorism budget, not by raiding the AIDS budget," says Daniel Kuritzkes, director of AIDS research at the Partners AIDS Research Center in Cambridge, Massachusetts.

Congress and the administration have been wrangling over the anthrax-vaccine

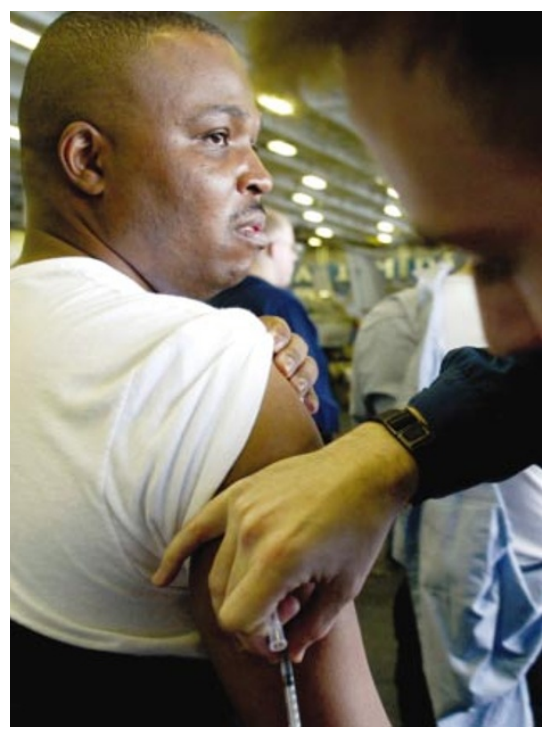

At the sharp end: anthrax vaccines for US troops are a high priority for the Bush administration.

project since February last year, when President Bush's budget request asked for $\$ 233$ million for the NIAID to spend on a vaccine. Congress denied the request and divided up the money between several parts of the National Institutes of Health. But the White House then demanded that the NIAID find a way to fulfil its request anyway.
In a letter sent to legislators on 2 July, White House budget director Joshua Bolten said that the NIAID would spend up to $\$ 117$ million this year and \$116 million next year on the "advanced development" of an anthrax vaccine, including the purchase of up to 9 million doses of vaccine.

The decision disappointed the Infectious Diseases Society of America, which says that the vaccine purchase could endanger the NIAID's larger research mission. The group argues that another branch of government, such as the Department of Homeland Security, should be paying for the vaccine.

On 11 July, Congressman Henry Waxman (Democrat, California) and Senator Jeff Bingaman (Democrat, New Mexico) wrote to the president protesting against the decision, which they called a "serious mistake".

But NIAID officials are putting on a brave face. "The Office of Management and Budget's position is that there is a critical need for the nation to rapidly develop a vaccine and there's nothing else out there to support this now," says Ralph Tate, the NIAID's budget director.

Janet Shoemaker, public-affairs director at the American Society for Microbiology, says NIAID officials are making the best of a difficult situation. "The anthrax issue has become less urgent in most people's minds, but in the minds of the people making the decisions it is still a very high priority," she says.

\section{Time runs short for opponents of chemical-testing rules}

\section{Glenn Murphy, London}

An unlikely alliance of animal-rights organizations and chemical-industry bodies is running out of time in its bid to stop a proposed chemical-testing plan from being implemented in Europe.

An eight-week consultation on the latest draft of the European Commission's new policy, which campaigners warn could lead to a massive increase in testing on animals, ended last week. Opponents of the legislation say they doubt whether any major changes will be made before the proposals go before the European Parliament later this year.

The draft contains details for a new Registration, Evaluation and Authorisation of Chemicals (REACH) system for all untested chemicals manufactured in the European Union (EU) in quantities over one tonne. The system would reverse the burden of proof, requiring manufacturers to demonstrate the safety of a new product.

The rules are being introduced in part to guide the assessment of existing chemicals, as European-level testing only began in 1981. Campaigners say that the process

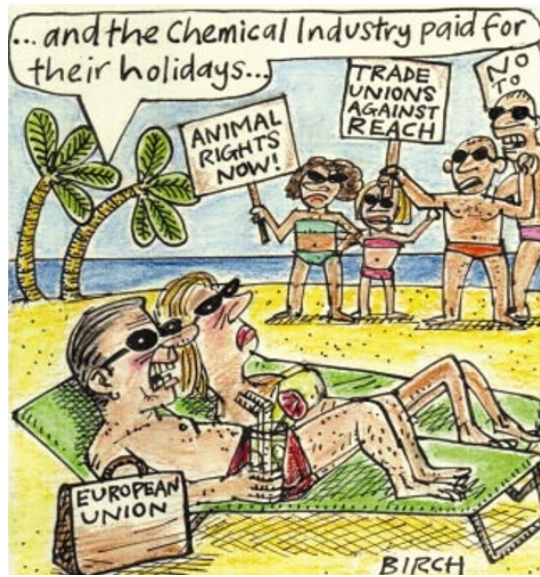

would involve the evaluation of more than 30,000 chemicals and could potentially take decades. Animal-rights groups estimate that more than 12 million animals would be needed (see Nature 418, 116; 2002).

Representatives from the chemical industry, trade unions and animal-rights organizations, who met in London last week to publicize their concerns, complain that the rules make no attempt to prioritize chemicals by looking at probable risks and existing data. The result, they say, will be duplication of tests and the redundant testing of everything from benzene to baking soda. Similar arguments have surrounded the introduction of a new testing regime in the United States (see Nature 395, 828; 1998).

The campaigners warn that chemical firms may relocate outside Europe. Chemicals imported to the EU will need to have REACH clearance, but products containing chemicals may not.

Commission officials say that a new testing system is badly needed in the interest of public health and that the legislation can still be amended. But campaigners fear that the draft will be rushed through before the European Parliament's term ends next May.

This doesn't bode well for those who want to change the rules, says Roger Jeary, national secretary of manufacturing for the London-based trade union Amicus. "Once you get to the stage of publishing draft legislation," he says, "the changes tend to be at the edges, rather than in the substance." 